\title{
Single-layer versus double-layer intestinal anastomosis: A comparative study
}

\author{
T Shah, RK Agarwal, RK Gupta, CS Agrawal, S Khaniya \\ Department of Surgery, B.P. Koirala Institute of Health Sciences, Dharan, Nepal
}

\begin{abstract}
Background: Intestinal anastomosis is essential to maintain the continuity after resection. There has been constant controversy due to various repair options. Adequate apposition can be achieved by either single- or double-layer anastomosis which may affect the post-operative outcome. Objective: To compare the outcome of single-layer versus double-layer anastomosis of small and large intestine. Method: This prospective comparative study was conducted over a period of 16 months, and included 78 patients who underwent intestinal anastomosis (without diverting stoma) after fulfilling inclusion and exclusion criteria. They were randomized into double-layer and single-layer intestinal anastomosis groups by a computer generated series. Double layer anastomosis was constructed using inner continuous Polyglactin 3-0 and outer interrupted Silk 3-0, while single layer anastomosis was done with interrupted PDS 2-0. Result: The mean age was $39.79 \pm 17.78$ years. A total of $59 \%$ were operated in emergency

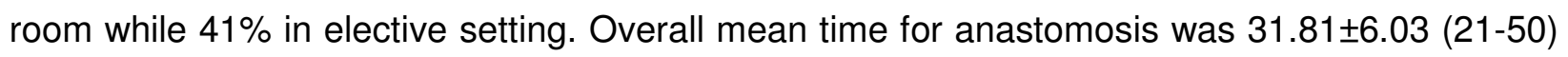
minutes. In double- and single-layer intestinal anastomosis mean time was 34.35 \pm 5.80 (26-50) and $29.13 \pm 5.08(21-45)$ minutes respectively, which was statistically significant ( $p$ value $<0.05)$. Single-layer was completed 5 minutes earlier than double layer anastomosis in average. Clinical anastomotic leak was seen in six (7.7\%) patients, three in each group. Eight (10.3\%) patients had surgical site infection: 3 in double-layer and 5 in single-layer groups. One (1.3\%) mortality was seen, from single-layer anastomosis group. Conclusion: Single-layer anastomosis can be constructed in significantly shorter time with similar complication rate when compared to doublelayer anastomosis.
\end{abstract}

Keywords: Anastomosis, double-layer, single-layer.

\footnotetext{
Address for correspondence

Dr. Tuhin Shah

Department of Surgery

B.P. Koirala Institute of Health Sciences, Dharan

Email:dr.tuhinshah@gmail.com
} 


\section{Introduction}

The ideal anastomotic technique and the suture material to be used is still an area of conflict for intestinal anastomosis after reaction. An ideal anastomosis should be easy to construct, reproducible, easy to teach, should not leak or obstruct and should regain the normal bowel function within a few days of its reconstruction.

Adequate apposition, adequate alignment, good local blood supply, tension free and equally spaced stitches can affect gastrointestinal anastomosis positively, while malnutrition, abdominal sepsis, generalized sepsis, and immune suppression can negatively affect the anastomosis. ${ }^{8}$ So, we can say that anastomotic integrity is an important determinant of immediate outcome in gastrointestinal surgery and the anastomotic technique to be an important aspect for its healing.

The various techniques included for repair of the intestinal tract are double layer inverted technique, double layer everted technique, single layer sero-submucosal technique, and single layer full thickness technique. It can also be repaired by the use of staplers, compression rings, metal wires and magnets. ${ }^{1-4}$ A Cochrane review done in 2012 concluded that single layer anastomosis is comparable to double layer anastomosis in terms of anastomotic leak, peri-operative complications, death rate and hospital stay; and consumes shorter operative time as compared to double layer. $^{5}$

In this study we have compared two methods of anastomosis, the single layer and the double layer anastomosis of the intestine and seen outcome and feasibility.

\section{Methods}

This study was conducted in the department of General Surgery at BPKIHS, Nepal from March 2012 to June 2013. This study was approved by the Institute's Ethical Review Board. Seventy- eight patients were enrolled using the Epi Info software with an alpha error of $0.05 \%$ and study power of 0.8 . All patients requiring resection and anastomosis of the intestine or stoma closure were enrolled in this study and were divided in two parallel randomized groups using a random computer generated series. The patients were included in the study after fulfilling the criteria and an informed written consent was taken from them. Inclusion criteria included patients requiring bowel resection and singlesite end-to-end anastomosis, or stoma closure. The patient excluded were those with polytrauma, multiple intestinal anastomosis, other associated visceral or head injury, anastomosis involving the esophagus, stomach, duodenum, pancreatico-hepatobiliary system, anastomosis with a diverting stoma and those who refused consent. 
All anastomosis in both groups was performed by three senior surgeons in the institute who had a minimum of 5 years of experience. Mechanical bowel preparation was done for all patients being operated in elective setting with polyethylene glycol solution given the night before the operation.

For double layer anastomosis polyglactin 2-0, on a round body needle, was used for the full thickness inner layer continuous anastomosis. Over and over suture was used to anastomose the bowel at $0.5 \mathrm{~cm}$ from the cut edge and $0.5 \mathrm{~cm}$ from each other. The second interrupted outer sero-muscular layer was constructed using silk 2-0. The suture was introduced $0.5 \mathrm{~cm}$ on either side of the first anastomotic layer and $0.5 \mathrm{~cm}$ from each other. This was done circumferentially around the inner continuous layer burying it inside. For single layer anastomosis Polysioxanone Suture (PDS) 2-0 on a round body needle was used. Full thickness bites were taken 0.5 $\mathrm{cm}$ deep from the cut end and $0.5 \mathrm{~cm}$ away from each other. If one of the bowel lumen was smaller than the other, anastomosis was facilitated by making an anti-mesenteric slit
(Cheat ling) to enlarge the smaller bowel lumen. A closed system soft tube abdominal drain was put in the pelvis.

The emergence of luminal contents either through the wound or from the abdominal drain, or a presence of collection near the anastomosis, causing fever, abscess, septicemia, metabolic disturbance and/or multiple-organ failure were labeled as an anastomotic leak.

Data was analyzed using the student t-test. The Fisher exact test and the Pearson chisquare test were used to analyze categorical data. $P$ value of less than 0.05 was considered as statistically significant.

\section{Results}

This study included 78 patients who underwent intestinal anastomosis (without diverting stoma). They were randomized into double-layer and single-layer intestinal anastomosis by a computer generated series. Forty patients were enrolled in double-layer and 38 patients were enrolled in the singlelayer anastomosis group. 


\section{Refused/Excluded}

Polytrauma $=6$

Multiple intestinal anastomosis $=3$

Other visceral injury $=3$

Anastomosis with a diverting stoma $=4$

Anastomosis involving esophagus, stomach, duodenum, pancreatico-hepatobiliary system $=2$

Associated with head injury $=2$

\section{Enrollment}

Sample size $(\mathbf{N}=\mathbf{7 8})$

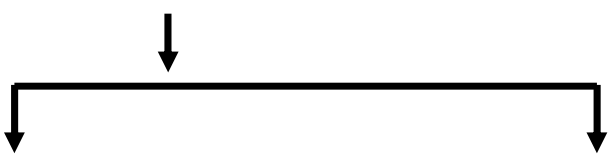

\begin{tabular}{|c|c|c|}
\hline & $\begin{array}{l}\text { Double layer anastomosis } \\
(\mathrm{N}=40)\end{array}$ & $\begin{array}{l}\text { Single layer anastomosis } \\
(\mathrm{N}=38)\end{array}$ \\
\hline \multirow[t]{3}{*}{ Allocation } & Bowel resection and & Bowel resection and \\
\hline & anastomosis = 38 & anastomosis $=26$ \\
\hline & Stoma closure = 2 & Stoma closure =12 \\
\hline \multirow{5}{*}{$\begin{array}{l}\text { Analysis } \\
\text { Per protocol }\end{array}$} & Treated & Treated \\
\hline & $n=40$ & $n=38$ \\
\hline & Surgical site infection= 3 & Surgical site infection $=5$ \\
\hline & Anastomotic leak $=3$ & Anastomotic leak = 3 \\
\hline & Mortality $=0$ & Mortality = 1 \\
\hline
\end{tabular}

Fig. 1: Flow diagram of the participants in the study

The age, sex, co-morbid conditions, anastomosis, are shown in Table 1. The diagnosis, operative setting and site of outcome variables (length of time required for 
anastomosis, anastomotic leak rate, morbidity and mortality rate) are shown in Table 2 . The management of the patients with clinical anastomotic leak is shown in Table 3. There was one mortality in single layer anastomosis group who had an ASA 3 score when he presented in the emergency. The patient had an anastomotic leak which was detected on day 7 post-operatively which was later reexplored and a stoma was created on postoperative day 11 . He expired on postoperative day 25 due to poor general physical condition. Preoperatively, he had chronic obstructive pulmonary disease (COPD) and was on inhalational medications on a regular basis.

Table 1: Comparison between study groups

\begin{tabular}{|c|c|c|c|}
\hline & $\begin{array}{c}\text { Double layer } \\
\text { anastomosis } \\
(n=40)\end{array}$ & $\begin{array}{l}\text { Single layer } \\
\text { anastomosis } \\
\quad(n=38)\end{array}$ & $P$ value \\
\hline Age (years) & $41.73 \pm 17.42$ & $37.76 \pm 18.16$ & 0.329 \\
\hline Gender (M/F) & $24 / 16$ & $25 / 13$ & 0.603 \\
\hline $\begin{array}{l}\text { Co-morbid condition } \\
\text { (DM, COPD) }\end{array}$ & 3,1 & 2,3 & \\
\hline \multicolumn{4}{|l|}{ Diagnosis } \\
\hline Trauma & 7 & 2 & \\
\hline Malignancy & 5 & 8 & \\
\hline Intussusception & 5 & 5 & \\
\hline Inflammatory & 16 & 7 & \\
\hline Stoma closure & 2 & 12 & \\
\hline Complicated hernias & 2 & 3 & \\
\hline Others & 3 & 1 & \\
\hline \multicolumn{3}{|l|}{ Operative setting } & \\
\hline - Elective & 8 & 24 & \\
\hline - Emergency & 32 & 14 & \\
\hline \multicolumn{3}{|l|}{ Site of anastomosis } & \\
\hline - small bowel to small bowel & 18 & 18 & \\
\hline - small bowel to large bowel & 18 & 11 & \\
\hline - large bowel to large bowel & 4 & 9 & \\
\hline
\end{tabular}


Table 2: Outcome variables

\begin{tabular}{|l|l|l|l|}
\hline & Double layer & Single layer & P value \\
\hline Number of patients & 40 & 38 & \\
\hline Time taken for anastomosis & $34.35 \pm 5.8$ mins & $29.13 \pm 5.08 \mathrm{mins}$ & 0.00 \\
\hline Clinical anastomotic leak & $3(7.5 \%)$ & $3(7.9 \%)$ & 0.949 \\
\hline Surgical site infection & $3(7.5 \%)$ & $5(13.2 \%)$ & 0.417 \\
\hline Mortality & 0 & $1(2.6 \%)$ & \\
\hline
\end{tabular}

Table 3: Comparison of anastomotic leak management

\begin{tabular}{|l|l|l|}
\hline \multicolumn{1}{|c|}{ Anastomotic leak management } & \multicolumn{1}{c|}{ Double layer } & \multicolumn{1}{c|}{ Single layer } \\
\hline Conservative & 2 & 0 \\
\hline Stoma & 1 & 2 \\
\hline Resection and anastomosis & 0 & 1 \\
\hline Total & 3 & 3 \\
\hline
\end{tabular}

\section{Discussion}

The outcome of bowel anastomosis is dependent on many important factors, both local and systemic. In a developing country like Nepal, proper technique of hand sewn anastomosis is a very crucial aspect for early healing and recovery. Also, the operative time taken plays a very important role for the early recovery and return to normal activity in the post-operative period. No data till date is available regarding the management of this problem in the eastern Nepal population, to the best of our knowledge, which has compared the safety and feasibility of the single layer anastomosis with the double layer intestinal anastomosis. ${ }^{6}$ Keeping all this in mind, we conducted this study to see the feasibility of single layer and double layer hand sewn anastomosis and its outcome.

A bulk of our patients were operated in the emergency setting, $59 \%$ versus $41 \%$ (which were done as an elective procedure). A study by Golub $\mathrm{R}$ et al., has mentioned that the likelihood of an anastomotic leak is higher in those patients who are operated in the emergency room. ${ }^{7}$ This correlates with our findings of 4 patients with anastomotic leak in the emergency setting and 2 patients with anastomotsic leaks in elective setting. In an emergency operation, the operating team may not always have the opportunity to optimize the patient. Gross bacterial or fecal 
contamination poses another hazardous setting and has a poorer outcome. ${ }^{8}$

In the meta-analysis by Shikata $S$ et al., the mean duration of anastomosis procedure in two included studies was $23.4 \mathrm{~min}$ vs. 36.9 min (single vs. two-layer). ${ }^{9} \mathrm{~A}$ mean of 20.8 minutes was required to construct a singlelayer anastomosis versus 30.7 minutes for the two-layer technique in a study reported by Burch et al. in 2000. ${ }^{10}$ Samel et al. reported suturing of a single layer anastomotsic took around 10-25 minutes. ${ }^{11}$ A time difference between the two techniques was also seen in our study. The mean time taken in double layer anastomosis was $34.4 \pm 5.8$ (26-50) minutes and in single layer anastomosis was $29.1 \pm 5.1 \quad(21-45) \quad$ minutes. A significant statistical difference $(p<0.05)$ in the anastomotic time taken between the two groups was noted in our study. The single layer anastomosis was completed at an average of almost 5 minutes earlier than double layer anastomosis.

Various studies have shown the rate of anastomotic leak in the single layer anastomosis group to be between 2- 45\% and in the double layer anastomosis group to be between 1.5 to $26 \% .^{12-20}$ Our results recorded a clinical anastomotic leak of $7.7 \%$; 3 each in double layer and single layer anastomosis groups, which is similar to the result of other reported studies. Of the 6 clinical anastomotic leaks, 2 of them were managed conservatively in double layer, while a re-operative procedure was performed on the remaining 4 patients. It was noted that 4 of the 6 anastomotic leaks occurred in the anastomosis involving the large bowel and the remaining 2 were of small bowel. A stoma was created in 3 patients on re-exploration, one in double layer and 2 in single layer anastomosis group. While in one patient from single layer anastomosis group underwent resection and re-anastomosis which was done in double layer technique. On comparing the anastomotic leak rates between the double layer and the single layer anastomosis groups, it was seen that the difference was statistically insignificant.

In this study, a surgical site infection of $10.3 \%$ was noted, 3 in double layer and 5 in single layer anastomosis groups which was managed conservatively. While a study reported the rate of surgical site infection of 1.5 to $7.7 \% .^{21}$

The mortality rate recorded in this study was $1.3 \%$. One patient expired in the single layer anastomosis group. This patient was a 78 year male operated for ileo-ileal intussusception in the emergency room. A stoma was created in this patient when a clinical anastomosis leak was noticed. The patient later succumbed to his poor general health condition on postoperative day 25 . Various studies have reported a mortality rate 
which ranges from $2-10 \% .^{12,16,21}$ The table other similar studies.

below (Table 4) compares our results with

Table 4: Collected series of single-layer and double layer anastomoses

\begin{tabular}{|c|c|c|c|c|c|c|}
\hline \multirow[b]{2}{*}{ Author } & \multirow[b]{2}{*}{ Year } & \multicolumn{5}{|c|}{ Single layer/ Double layer } \\
\hline & & $\begin{array}{c}\text { Mean age } \\
\text { (years) }\end{array}$ & $\begin{array}{l}\text { Males } \\
\text { (in \%) }\end{array}$ & $\begin{array}{c}\text { Duration of } \\
\text { anastomosis } \\
\text { (minutes) }\end{array}$ & $\begin{array}{l}\text { Leak } \\
(\%)\end{array}$ & $\begin{array}{c}\text { Mortality } \\
(\%)\end{array}$ \\
\hline Irvin et al. ${ }^{19}$ & 1973 & $64.0 / 57.0$ & $41.4 / 54.8$ & NR & $17 / 16$ & $10 / 10$ \\
\hline Everett et al. ${ }^{141}$ & 1975 & $64.0 / 62.5$ & $43.1 / 47.0$ & NR & $15 / 25$ & NR/ NR \\
\hline $\begin{array}{l}\text { Goligher et } \\
\text { al. }^{142}\end{array}$ & 1977 & $63.4 / 63.5$ & $42.0 / 37.9$ & NR & $45 / 26$ & $N R / N R$ \\
\hline Maurya et al. ${ }^{111}$ & 1984 & $29.8 / 31.6$ & $60.0 / 62.5$ & NR & $7 / 18$ & $\mathrm{NR} / \mathrm{NR}$ \\
\hline Alves et al. ${ }^{100}$ & 1999 & 54/ ND & $50.03 / \mathrm{ND}$ & NR & $6 / N D$ & 2/ ND \\
\hline Burch et al. ${ }^{101}$ & 2000 & $44.3 / 44.7$ & 64.6/59.7 & $20.8 / 30.7$ & $3.1 / 1.5$ & $\mathrm{NR} / \mathrm{NR}$ \\
\hline Moriura et al. ${ }^{112}$ & 2002 & $65.5 / \mathrm{ND}$ & NR & NR & $1.5 / \mathrm{ND}$ & $0 / N D$ \\
\hline $\begin{array}{l}\text { Hussain et } \\
\text { al. }^{133}\end{array}$ & 2008 & $56 / N D$ & $54.1 / \mathrm{ND}$ & NR & 1.8/ND & $0 / N D$ \\
\hline Ahmad et al. ${ }^{136}$ & 2013 & NR & $80 / \mathrm{ND}$ & NR & $8 / \mathrm{ND}$ & $8 / N D$ \\
\hline Present & 2013 & $37.8 / 41.7$ & $65.8 / 60$ & $29.1 / 34.4$ & $7.9 / 7.5$ & $2.6 / 0$ \\
\hline
\end{tabular}

NR: not recorded

ND: not done

\section{Conclusion}

Intestinal anastomosis has always been a crucial surgical skill for a general surgeon. Anastomotic leak has been bothersome to the surgeons in the post-operative period and, whenever present, it has a high morbidity and mortality. Single-layer anastomosis saves valuable intra-operative time with similar complications when compared to double-layer anastomosis.

\section{References}

1. Irvin TT, Edwards JP. Comparison of single- layer inverting, two- layer inverting, and everting anastomosis in the rabbit colon. $\mathrm{Br} J$ Surg. 1973; 60(6): 453-57

2. Goligher JC. Surgery of the Anus, Rectum and Colon. In: Goligher JC editor(s). Surgery of the Anus, Rectum 
and Colon. 1. London: Bailliere, Tindall \& Cassel. 1967: 522.

3. Muir EG. Operative Surgery. In: Muir EG editor(s). Operative Surgery. 1., London. 1969: 655.

4. Turnbell RB, Kyle K. Operative Surgery. In: Turnbell RB, Kyle $\mathrm{K}$ editor (s). Operative Surgery. 1., London: Butterworths. 1969: 663.

5. Sajid M, Siddiqui M, Baig MK. Single layer versus double layer suture anastomosis of the gastrointestinal tract. Cochrane Database of Systematic Reviews. 2010, Issue 10.

6. National Center for Biotechnology Information, U.S. National Library of Medicine.

7. Golub R, Golub RW, Cantu R, Stein HD. A multivariate analysis of factors contributing to leakage of intestinal anastomoses. J Am Coll Surg. 1997; 184: 364-372.

8. Sheridan CB, Zyromski N, Matter S. How to always do a safe anastomosis. Contemporary Surgery. 2008; 64(2).

9. Shikata $S$, Yamagishi $H$, Taji $Y$, Shimada T, Noguchi Y. Single- versus two- layer intestinal anastomosis: a meta-analysis of randomized controlled trials. BMC Surgery. 2006; 6:2 .

10. Burch JM, Franciose RJ, Moore EE, et al. Single-layer continuous versus twolayer interrupted intestinal anastomosis:
A prospective randomized trial. Ann Surg 2000; 231: 832-7.

11. Samel ST, Heinrich A, Becker H, Post S. Continuous Single-layer Anastomoses with Monofilament Poliglecaprone Sutures in Abdominal Surgery. Eur J Surg 1999; 165: 710711.

12. Irvin TT, Goligher JC, Johnston D. A Randomized Prospective Clinical Trial Of Single-Layer And Two-Layer Inverting Intestinal Anastomoses; Brit. J. Surgery. 1973; 60; 6, 457-60

13. Everett WG. A comparison of one layer and two layer technique for colorectal anastomosis. Br J Surg 1975, 62: 135140.

14. Goligher JC, Lee PW, Simpkins KC, Lintott DJ: A controlled comparison oneand two-layer techniques of suture for high and low colorectal anastomoses. Br J Surgery. 1977, 64: 609-614.

15. Maurya SD, Gupta HC, Tewari A, Khan SS, Sharma BD: Double layer versus single layer intestinal anastomosis: a clinical trial. Int Surg. 1984, 69: 339340.

16. Alves $A$, Panis $Y$, Pocard $M$, Regimbeau JM, Valleur P. Management of anastomotic leakage after nondiverted large bowel resection. J Am Coll Surg. 1999; 189: 554-559 
17. Burch JM, Franciose RJ, Moore EE, et al. Single-layer continuous versus twolayer interrupted intestinal anastomosis: A prospective randomized trial. Ann surgery. 2000; 231:832-7.

18. Moriura S, Kobayashi I, Ishiguro S, Tabata T, Yoshioka Y, Matsumoto T. Continuous mattress suture for all handsewn anastomoses of the gastrointestinal tract. Am J Surg 2002; 184: 446-8.

19. Hussain A, Mahmood H, Nicholls J, ElHasani S. Continuous figure-of-eight suturing in upper and lower gastrointestinal anastomosis.

Singapore Med J. 2008; 49(9) : 672

20. Ahmad M, Amer S, Alam S, Ullah A, Sadiq MU, Khan MA. Safety of single layer continuous extra mucosal Gut anastomosis in emergency. J Postgrad Med Inst 2013; 27(1): 69-73.

21. Sarin S, Lightwood RG : Continuous single-layer gastrointestinal anastomosis: a prospective audit; $\mathrm{Br}$. J. Surg. 1989; 76: 493-495 